\title{
FAMILIAS NA PERIFERIA DE MAPUTO (MOÇAMBIQUE): ANÁLISE DE RELAÇÕES E COMPORTAMENTOS SÓCIO-ECONÓMICOS EM CONTEXTO DE MUDANÇA
}

\author{
Dra. D. ${ }^{a}$ Ana Benard da Costa \\ Bolseira da Fundação da Ciência e Técnologia \\ Universidad Técnica. Lisboa. Portugal
}

Partindo de um trabalho campo realizado num bairro periférico da cidade de Maputo cm Julho e Agosto de 1999, pretende-se, ncsta comunicação, aprofundar temáticas relacionadas com a transformação de comportamentos sócio-cconómicos em contexto de mudança c a forma como estes transparecem nas práticas c estratégias de sobrevivência c reprodução desenvolvidas ao nível dos grupos familiares. Simultancamente, pretende-se questionar a pertinência da escolha de determinada unidade de análise em detrimento de outras face aos objectivos da investigação e a aplicabilidade dos conceitos teóricos fundamentais (agregados familiares, famílias, estratégias) ao universo $\mathrm{em}$ estudo.

\section{INTRODUÇÃO'}

O bairro de Mafalala é um dos muitos bairros de "caniço" da cidade de Maputo e foi um dos três bairros onde, em conjunto com 7 elementos da equipa interdisciplinar do projecto "Urbanização Acelerada em Luanda e Maputo: Impacto da Guerra e das Transformações Sócio-Económicas (anos 80-90)" efectuei trabalho de campo durante os

1 A presente comunicação decorre de investigações realizadas com vista à preparação da minha Tese de Doutoramento em Estudos Africanos que se articula, na sua fase inicial, com o projecto interdisciplinar "Urbanização acelerada em Luanda e Maputo: impacto da guerra e das transformações sócio - económicas nas décadas de 80 e 90 ". Este projecto é realizado pelo CESA (Centro de Estudos sobre África e do Desenvolvimento) do ISEG-UTL e conta com a participação de uma equipa de 11 investigadores portugueses de diferentes áreas académicas (sociólogos, antropólogos, economistas e arquitectos urbanistas) c por colaboradores de ambos os paises africanos. Ambas as investigações estão a ser realizadas com o apoio financeiro da Fundação da Ciência e Tecnologia (Programa PRAXIS XXI). 
meses de Julho e Agosto de 1999. Esta equipa, composta por investigadores de diferentes áreas académicas (sociólogos, antropólogos, economistas e arquitectos urbanistas) realizou neste bairro 23 entrevistas a 23 famílias, onde se obtiveram informações sobre os diferentes aspectos da realidade que se relacionavam com os objectivos do projecto e os interesses de investigação de cada um dos intervenientes.

Os objectivos do projecto em causa (e o tempo disponivel para o trabalho de campo) não permitiram a realização de um estudo muito aprofundado da problemática subjacente a esta comunicação, mas a informação obtida possibilita, por um lado, direccionar de forma mais contextualizada, a posterior pesquisa de terreno para aspectos que se pretendem desenvolver em profundidade e, por outro, traçar um primeiro "retracto" da temática que se pretende investigar. E é esse "retracto" que se apresenta nesta comunicação

\section{O BAIRRO DE MAFALALA}

O bairro de Mafalala fica situado no Distrito Urbano 3 da cidade de Maputo ${ }^{2}$ A sua origem remonta ao princípio do século XX e é um dos bairros mais antigos desta cidade. Por esse facto, e por nele terem nascido ou residido algumas das importantes personagens da vida de Moçambique, é considerado um bairro histórico.

Em meados do século $\mathrm{XX}$, começou a albergar um número crescente de populações vindas do norte de Moçambique e muitos destes e dos seus descendentes ainda aí residem. No periodo anterior à independência contava um número relativamente grande de "assimilados"3 e o conjunto destas características conferiam-lhe, e ainda conferem, uma certa originalidade, quer em termos da sua população residente, quer em termos da arquitectura de muitas das casas aí existentes. Contrariamente ao que era regra no tempo colonial - onde as casas dos africanos nos bairros periféricos, eram, na sua maioria térreas, de planta rectangular e paredes de caniço - muitas das casa em Mafalala eram em madeira e zinco espelhando o poder económico relativamente mais elevado dos seus habitantes em relação aos habitantes dos outros bairros. Actualmente $30 \%$ das habitações no bairro são neste material mas é notório o estado de degradação em que muitas se encontram. Paralelamente, e á semelhança do que acontece noutros bairros suburbanos, muitas das casas em caniço e de madeira e zinco tem vindo a ser substituídas por casas de alvenaria (que no tempo colonial só podia ser utilizada em casas de régulos ou de funcionários coloniais) (RAPOSO \& QUNTELA, 2000).

2 A cidade de Maputo tem 66 bairros divididos por 5 Distritos Urbanos

3 De acordo com o Estatuto dos Povos Coloniais das Possessões Portuguesas em África, de 1954, era considerado "assimilado" todo o africano que: tivesse mais de 18 anos; falasse correctamente a lingua portuguesa; exercesse uma profissão da qual tirasse o rendimento necessário à subsistência própria e das pessoas da sua familia a seu cargo ou possuisse bens suficientes para o mesmo fim; tivesse um bom comportamento e tivesse adquirido a educação e os costumes necessários à aplicação integral do direito público e privado dos cidadãos portugueses. Os restantes africanos eram considerados «indigenas» e não cidadãos de pleno direito.(CASTRO, 1980:413) 
A situação em termos populacionais tem-se vindo a transformar de forma significativa. Após a independência os entraves que existiam à fixação dos africanos nas cidades diminuíram (embora posteriormente novos entraves tenham surgido) e a população deste bairro (como de outros) aumentou e posteriormente, devido à guerra civil, o bairro recebeu muitos "deslocados" provenientes das províncias do Sul do país.

O Bairro de Mafalala fica praticamente no centro da cidade mas, apesar desta proximidade (e talvez por isso) e do seu carisma histórico, não é um local isento de problemas. $\mathrm{O}$ alto nível freático da zona dificulta a drenagem das águas pluviais que inundam mais de metade do bairro na época das chuvas e a situação agrava-se, ano após ano, pois as valas de drenagem estão obstruídas ou por falta de limpeza ou por nelas se terem construído habitações.

De acordo com o Censo em 1997 viviam em Mafalala de 21.189 pessoas. Mas como é que vivem estas pessoas? De que vivem? Como se reproduzem socialmente? Como se forma e se constrói a sua identidade? Como foram socializados e que valores e costumes transportam? Em que mudanças se traduz o processo de urbanização em que estão envolvidos e que transformações podemos observar nos seus comportamentos sócio económicos e de que forma estas transparecem nas estratégias de sobrevivência e reprodução que desenvolvem? E como estudar tudo isto? Quais os conceitos a aplicar e que unidade de análise escolher?

\section{CONCEITO DE FAMÍLIA}

Ao pretender fazer uma análise sobre a transformação de comportamentos sócio económicos em contexto de mudança e sobre a forma como estes transparecem nas estratégias de sobrevivência e reprodução desenvolvidas por grupos de indivíduos, um dos problemas fundamentais com que me debato é o da escolha da unidade de análise.

Em trabalhos anteriores, constatei que a unidade de análise utilizada normalmente neste tipo de investigações - o agregado familiar' (household)- era insuficiente, pois os comportamentos, as praticas e as estratégias de sobrevivência e reprodução desenvolvidas por os membros de um agregado familiar, implicam outros actores que por definição estão excluídos desta unidade de análise.

4 Bryceson define agregado familiar (household) como: “(...) uma identidade colectiva formada por um grupo de individuos unidos pelo acesso comum a recursos e partilhando uma ou mais das seguintes caracteristicas: um orçamento comum resultante de uma menor ou maior partilha de rendimentos, uma cozinha comum e/ou residência comum." (BRYCESON,1995:39) e tenta, deste modo, ultrapassar as limitações - constatadas nomeadamente por Yanagisako (1979:164) - das definições "clássicas" (por exemplo a de Bender 1967:493) que consideravam a co-residência como referente principal deste conceito. Esta definição possibilita, de facto, uma visão mais dinâmica dos agregados familiares, pois coloca diferentes dimensões em alternativa, mas não deixa de ser, por um lado, demasiado redutora da realidade e por outro lado, demasiado abrangente. Nesta definição o agregado familiar é, fundamentalmente, definido do ponto de vista material e económico. Os laços e as relações familiares e de parentesco que estão na sua base e que são o seu fundamento "são esquecidos", o que leva a que em última análise outros agregados populacionais como sejam os quartéis, internatos ou conventos... possam ser considerados agregados familiares 
Se o conceito de "household" tem limitações, o conceito de família surge como alternativa, mas não deixa de colocar alguns problemas. Ao definir a família estritamente em termos genealógicos e de parentesco dificilmente a podemos delimitar e está-se, como refere Yanagisako, a partir do princípio que a reprodução é a sua função primária, quando estas “(...) são inegavelmente mais do que procriação e socialização. São também, produção, troca, poder, desigualdade e status(...)" (YANAGISAKO,1979:199).

Cada um destes conceitos - "familia", "agregado familiar" - é insuficiente ou demasiado vago para traduzir, por si só, as unidades sociais que se pretende analisar. Paralelamente, os objectivos da análise não permitem hierarquizar ou ignorar uma ou mais das diferentes dimensões (reprodutivas, económicas, simbólicas, políticas, residenciais, de parentesco...) contidas nestas unidades sociais, de modo a utilizar exclusivamente um conceito em detrimento dos outros consoante a dimensão em estudos.

Assim, talvez não haja outra alternativa senão concordar com Yanagisako (1979:191) quando este defende que o conceito de família e o de agregado familiar, deverão ser apenas conceitos "ad hoc", como por exemplo os termos de casamento e parentesco. Mas, nesse caso como se poderão estabelecer comparações entre os dados da análise e dados sobre o mesmo contexto ou sobre contextos similares, ou não, provenientes de outras fontes?

Com extremo cuidado, tendo consciência em cada caso daquilo que se pretende comparar, é possível estabelecer "pontes" utilizando os "instrumentos de trabalho" disponiveis. Afinal, não tenho alternativas a propor d utilização dos conceitos que aqui questiono, e conhecer as suas limitações não inviabiliza a sua utilização, apenas contribui para que a análise seja mais critica e cuidada.

Assim, a opção conceptual é de partir do agregado familiar para chegar à família, elegendo esta última, sem a definir de forma precisa, como unidade de análise da investigação. Não se pode prescindir do conceito de agregado familiar pois a realidade social que traduz, facilmente apreensivel à investigação empirica, dada as suas características materiais, permite (eventualmente) chegar à família, entidade bastante mais fluída no tempo e no espaço e inconstante nas suas formas, mas, dentro da qual, se poderá (eventualmente) apreender a totalidade das relações e dinâmicas envolvidas no processo de mudança de comportamentos e nas estratégias de sobrevivência e reprodução accionadas pelas populações em causa.

Esta opção teórica acarreta uma serie de dificuldades, nomeadamente ao nível da análise empírica. Como delimitar as fronteiras das familias?

Por exemplo, em trabalhos de campo já realizados, constatei que várias famílias mantinham as suas terras de cultivo (macahambas) nas zonas rurais e que se deslocavam com

5 Pode-se refutar este argumento considerando que é possivel hierarquizar as diferentes dimensões, destacar as de maior relevância face a um dado contexto e aos objectivos da análise e, a partir dai, fazer uma opção conceptual. Por exemplo, Loforte faz esta operação e opta pelo conceito de unidade doméstica pois "(...) esta unidade, enquanto lugar de pertença dos individuos, de produção, de consumo e gestão de bens comuns, tem mais relevância do que os laços de identificação familiar." (LOFORTE,1996:74) 
regularidade até lá, aí permanecendo uns tempos, para as cultivarem e assim obterem produtos para venda ou auto consumo. Quando se deslocivam para o campo levavam produtos da "cidade" para os parentes que aí residiam e que tomavam conta das terras na sua ausência. Esta troca e entre-ajuda, contribuí para a sobrevivência dos familiares que residem no campo e dos que residem na cidade. Será que se deve considerar todos os beneficiários destas trocas como membros de uma familia ou só alguns?

Por enquanto, ainda não existe resposta para esta questão, mas considero preferível, apesar das dificuldades e riscos que isso acarreta, utilizar uma unidade de análise "aberta" do que condicionar a investigação, utilizando conceitos redutores e que não se aplicam ao contexto e à problemática em questão.

A família é elegida como unidade de análise, pois quer as dinâmicas que se processam no interior dos agregados familiares, ou entre estes e o exterior, quer as identidades sociais que aí são constituídas, podem ser interdependentes de importantes relações, de diversa ordem, com membros da família que por definição não pertencem ao agregado. E, só a percepção da totalidade das relações que intervêm nesse processo, que o condicionam, estão na sua base e que com ele se desenvolvem, pode ajudar a compreender o processo de mudança de comportamentos sócio económicos e as estratégias de sobrevivência e reprodução de familias na periferia de Maputo.

\subsection{Poposta de tipologia}

Tendo em conta todas as dificuldades conceptuais referidas, apresento uma proposta de tipologia de famílias. A tipologia permite uma primeira organização dos dados empíricos, necessariamente provisória, pois o aprofundamento do trabalho de campo levará certamente a uma reclassificação das famílias em função de nova informações. Assim a proposta é a seguinte:

- Familias monoparentais, formadas por pai e filhos ${ }^{6}$ ou mãe e filhos.

- Familias nucleares, formadas por pai, mãe e filhos. Consideramos, igualmente, como pertencentes a esta categoria, familias de casais sem filhos.

- Familia extensas patrilineares, quando os filhos casados continuam com as suas mulheres e respectivos filhos a "pertencer" ao grupo do pai.

- Família extensa matrilinear, composta pelos cônjuges e pelas respectivas filhas casadas com os seus maridos e filhos.

- Família alargada, consideramos como fazendo parte deste tipo as famílias com qualquer composição diferente da anterior

6 É evidente que estamos a considerar os laços sociais e não a relação física (biológica) entre pais e filhos, este facto é importante pois a adopção é ainda uma prática corrente entre os povos africanos. 


\section{CONCEITO DE ESTRATÉGIA}

$\mathrm{Na}$ análise sobre o processo de mudança de comportamentos sócio económicos e as estratégias de sobrevivência e reprodução de familias, utiliza-se com frequência o conceito de estratégia e, à semelhança do que se fiz com o conceito de familia, levanto aqui algumas questões. Isto justifica-se, pois este termo tem tido uma utilização recorrente em ciências sociais sem, na maior parte dos casos, haver a preocupação de lhe precisar o sentido. Este conceito tem sido empregue para designar conjuntos de acções desenvolvidas por individuos particulares, grupos sociais, instituições, estruturas de diverso tipo, etc. E, se de um modo geral, "estratégia", pressupõe escolha entre alternativas, intencionalidade "consciente" e "racional", também é verdade que se fala de estratégias inconscientes, por exemplo, em relação a crianças ou a doentes mentais. Paralelamente, certo tipo de acções aparentemente "incoerentes" ou "irracionais", podem ser, à posteriori, consideradas estratégias, quando são analisados os contextos (políticos, sociais, culturais, psicológicos....) em que estas foram desenvolvidas e que por isso lhes dão sentido.

Por outro lado, como refere Crow (1989:2), uma das dificuldades da apreensão do conceito, no sentido acima referido - conjunto de aç̧ões articuladas de forma coerente e espelhando um qualquer tipo de racionalidade - prende-se com a unidade que se quer analisar e aqui a questão é a de saber, até que ponto, entidades sociais colectivas, como famílias, podem ser tratados como actores sociais ou como entidades homogéneas, capazes de expressar nas suas acções uma atitude racional colectiva e não individual.

E de facto, as famílias não são entidades homogéneas, são associações de indivíduos e as estratégias que desenvolvem (sejam de trabalho, de sobrevivência, ou outras) resultam de um processo dinâmico que pode implicar diversos tipos de conflitos, de negociações e de consensos, entre os membros que as compõem. E aquilo que à priori se considera como estratégias de familias, podem ser estratégias individuais, isto é, estratégias que derivam da vontade de indivíduos particulares no seio da família e que estes impõem aos outros. Neste caso, seria importante compreender até que ponto servem ou não os interesses da familia.

As dificuldades de análise, derivadas do facto de as famílias serem mais do que a soma das suas partes mas menos do que um todo homogéneo, não podem impedir de reconhecer a existência de conjuntos articulados e coerentes de acções, desencadeadas com vista a concretização de objectivos que servem os interesses da família como um todo. Essas acções e a sua articulação e coordenação, não podem ser só fruto de "felizes coincidências", de meros acasos, ou da repetição de formulas já testadas, mas resultam também de uma avaliação realizada ao nivel da familia (por consenso, imposição, conflito ou negociação) dos recursos disponíveis, dos constrangimentos existentes e dos seus possiveis resultados. E é a existência de todo este processo, que pode, obviamente, não ser linear mas dinâmico, que permite classificar um conjunto de acções ou de práticas das familias, como estratégicas. Mas a questão da intencionalidade dos actores, do grau de consciência e de racionalidade que as suas aç̧ões traduzem, é uma questão complexa, e nem sempre é fácil determinar até que ponto estes estão conscientes das suas escolhas e de que estas resultam de opções deliberadas entre varias práticas possíveis. 
Tentando contornar este problema, Olivier de Sardan (1998:127) considera que uma estratégia pode ser deduzida à posteriori pelo investigador, independentemente do facto de existir, ou não, uma intencionalidade consciente, por parte dos sujeitos da acção. Seguindo esta orientação, considera-se que não é necessário que os sujeitos da acção tenham plena consciência de que um conjunto de práticas, por eles accionadas, constitui uma estratégia particular, para estas efectivamente o serem. É a coerência entre estas e a capacidade que têm de encadeadas, atingirem um objectivo determinado que as define como estratégicas ou não.

\subsection{Estratégias de sobrevivência c reprodução}

As estratégias de sobrevivência e reprodução, podem ser definidas, ainda que de uma forma muito vaga, como um conjunto articulado de praticas distintas realizadas por membros de uma família com vista à sua sobrevivência e reprodução.

Estas práticas (sociais e culturais) entendidas como maneiras de fazer e de agir em situação (LE BRIS, 1987:262), ao serem articuladas coerentemente nos diferentes níveis da vida dos indivíduos e dos grupos, de modo a garantir a sua sobrevivência e reprodução, originam "estratégias" que podem ser mais ou menos conscientes ou "racionais". Tendo em conta que a racionalidade dos indivíduos é limitada pois estes "decidem com informação limitada, e com aspirações também limitadas, decorrentes dos quadros de referência que são capazes de manipular" (PIRES, 1993:3)

Para se compreenderem as estratégias de sobrevivência e reprodução, de um grupo familiar como um todo, ou de indivíduos particulares no seu seio, é fundamental ter uma noção de racionalidade simultaneamente plural e limitada e uma abordagem dinâmica que permita apreender, numa perspectiva diacrónica, as trajectórias de grupo e individuais e as mudanças estruturais no contexto.

No universo em estudo, o processo de mudança originou o desenvolvimento de estratégias de sobrevivência e reprodução que são essencialmente estratégias de risco (e que espelham a situação de crise e de mudança de que são resultantes) pois contêm em si, simultânea e paradoxalmente, os factores que possibilitam a sobrevivência e a reprodução da família e os factores que contribuem para a sua desagregação.

Para sobreviverem e para se reproduzirem socialmente, em situação de crise económica e social, as famílias tem de diversificar as suas fontes de rendimento e as suas redes de solidariedade. Por isso, não só dispersaram os diferentes membros por diferentes actividades produtivas, como, $\mathrm{o}$ facto de estas se desenvolverem em espaços diferentes (geográficos e não só), possibilita a inserção em diferentes redes sociais. Simultaneamente, existem alguns elementos "pivot", (itenerantes) que circulam entre alguns destes diferentes espaços, inserindo-se em diferentes redes, estabelecendo os elos de ligação indispensáveis e alguns niveis de coordenação, entre o conjunto complexo destas relações sociais e actividades económicas. Mas essa dispersão é uma ameaça constante à coesão do grupo, pois os núcleos dispersos podem autonomizar-se, e por isso estas estratégias põem em risco os objectivos que pretendem atingir. 


\section{FAMÍlIAS NO BAIRRO DE MAFALALA}

De acordo com o Censo, viviam em Mafalala, em 1997, 21.189 pessoas distribuídas por 3.996 agregados familiares. Sendo mais de metade (2.298) considerados pelo Censo agregados familiares alargados, 893 nucleares, 383 monoparentais, 411 unipessoais e 20 de outro tipo.

O Censo de 97, diz-nos também (para a semana de referência), que em 12.924 pessoas com mais de 15 anos de idade, 7.024 trabalhavam, 2.583 eram domésticos, 1.873 estudantes, 290 reformados, 66 ajudavam familiares e os restantes, procuravam emprego, eram incapacitados, não trabalhavam, etc.

Mas o que significam estes dados? Será que os domésticos não desenvolvem actividades geradoras de rendimentos? Será que os ajudam familiares, os estudantes, os reformados e os desempregados, não trabalham? Será que uma pessoa não desenvolve simultaneamente várias actividades?

As informações (Quadro $\mathrm{n}^{\circ} 1$ ) do trabalho de campo confirmam estas suposições. A pluriactividade existe com alguma frequência - 10 famílias têm um ou mais dos membros a trabalhar em duas ou mais actividades geradoras de rendimentos - e numa família são vários aqueles que desenvolvem actividades que directamente ou indirectamente originam rendimentos ou bens de consumo, mesmo que estes sejam geridos por um ou dois membros responsáveis pela actividade em questão.

Quadro n'1

\begin{tabular}{|c|c|c|c|c|}
\hline Famílias & Tipo de familia & $\begin{array}{l}N^{\circ} \text { de membros } \\
\text { da família }\end{array}$ & $\begin{array}{l}\mathrm{N}^{\mathrm{o}} \text { de membros } \\
\text { da familia que } \\
\text { trabalham }\end{array}$ & $\begin{array}{l}\text { Pessoas } \\
\text { com mais de } \\
\text { uma actividade }\end{array}$ \\
\hline$N^{0} 1$ & Alargada & 16 & 5 & 3 \\
\hline $\mathrm{N}^{2} 2$ & Alargada & 3 & 3 & \\
\hline$N^{0} 3$ & Não há informações & $2 ?$ & 1 & 1 \\
\hline $\mathrm{N}^{\circ} 4$ & Alargada & 6 & 2 & 1 \\
\hline$N^{0} 5^{a}$ & Alargada & 17 & 3 & \\
\hline$N^{0} 6$ & Alargada & 12 & 3 & \\
\hline$N^{07}$ & Nuclear & 10 & 2 & 1 \\
\hline$N^{0} 8$ & Nuclear & 2 & 2 & 2 \\
\hline$N^{\circ 9}$ & Alargada & 9 & 3 & 3 \\
\hline $\mathrm{N}^{\circ} 10$ & Nuclear & 2 & 1 & \\
\hline $\mathrm{N}^{\circ} 11$ & Alargada & 7 & 1 & \\
\hline$N^{\circ} 12$ & Alargada & 12 & 3 & \\
\hline $\mathrm{N}^{\circ} 13$ & Alargada & 11 & $5+$ & 2 \\
\hline $\mathrm{N}^{\mathrm{D}} 14$ & Alargada & 11 & 3 & \\
\hline $\mathrm{N}^{\circ} 15$ & Alargada patrilinear & 12 & 6 & 2 \\
\hline $\mathrm{N}^{\circ} 16$ & Nuclear & 3 & 2 & 1 \\
\hline $\mathrm{N}^{\circ} 17$ & Alargada & 3 & 2 & \\
\hline
\end{tabular}




\begin{tabular}{|l|l|l|l|l|}
\hline Familias & Tipo de família & $\begin{array}{l}\mathrm{N}^{\circ} \text { de membros } \\
\text { da familia }\end{array}$ & $\begin{array}{l}\mathrm{N}^{\circ} \text { de membros } \\
\text { da familia que } \\
\text { trabalham }\end{array}$ & $\begin{array}{l}\text { Pessoas } \\
\text { com mais de } \\
\text { uma actividade }\end{array}$ \\
\hline $\mathrm{N}^{\circ} 18$ & Nuclear & 6 & 2 & \\
$\mathrm{~N}^{\circ} 19$ & Alargada & $4+$ & $2+$ & 1 \\
$\mathrm{~N}^{\circ} 20$ & Alargada & 8 & 2 & \\
$\mathrm{~N}^{\circ} 21$ & Alargada & 5 & 1 & \\
$\mathrm{~N}^{\circ} 22$ & Alargada & $4+$ & 2 & \\
$\mathrm{~N}^{\circ} 23$ & Monoparental & 7 & 2 & \\
\hline
\end{tabular}

No Quadro n. 2 pode observar-se que, em 18 das famílias, há um ou mais dos membros com uma actividade "formal" desenvolvida em meio urbano (sem considerar aqui a actividade agrícola em machambas familiares) ou na reforma e, em 16 dessas familias, existem pessoas a desenvolver outro tipo de actividades. No conjunto das familias, apenas 4 declararam que viviam somente de rendimentos provenientes de trabalho no chamado sector formal da economia urbana e, numa dessas familias, os rendimentos eram provenientes do subsídio do INAS (ex GAPVU') e das remessas de um imigrante na África do Sul. E 8 destas familias tinham membros emigrados noutros países que, ou enviavam dinheiro para ajudar a família de Mafalala, e/ou quando vinham de visita traziam "presentes".

$O$ que se pode concluir desta pequena amostra, é que em praticamente todas as famílias, existem alguns membros que trabalham num conjunto de actividades geradoras de rendimentos que são realizadas de modo "informal" e/ou são de auto-consumo, como é o caso da produção agrícola das machambas familiares. Assim, é interessante notar, que 11 destas familias têm bancas de vendas dos mais variados produtos à porta de casa ou vendem noutros locais "informais" (bares informais ou na estrada), 8 desenvolvem outro tipo actividades geradoras de rendimentos em casa (são curandeiros, tem pequenas oficinas...) e 10 beneficiam de produtos agrícolas provenientes de machambas exploradas directamente por eles ou por outros familiares residentes no campo.

7 Não cabe dentro dos objectivos desta comunicação o tratamento desta temática, intimamente relacionada com este estudo, mas não podemos deixar de referenciar que questões como, o que deve, ou pode ser considerado como fazendo parte do sector formal da economia ou do sector informal, são complexas, assim como são complexas as relações que se processam entre estes dois sectores e merecem, por isso um tratamento aprofundado e reflectido.

8 O GAPVU (Gabinete de Apoio às Populações Vulneráveis Urbanas) foi criado em 1988 e em 1997 transformado em INAS (Instituto Nacional de Acção Social). Através deste esquema são distribuidos subsidios aos agregados familiares urbanos considerados mais vulneráreis que são seleccionados de acordo com alguns critérios. 
Quadro n'2

\begin{tabular}{|c|c|c|c|c|c|}
\hline Famillas & $\begin{array}{l}\text { Trocas cidade- } \\
\text { campo }\end{array}$ & Vendas & $\begin{array}{l}\text { Actlvidade "formal" } \\
\text { (no activo ou } \\
\text { reformado) }\end{array}$ & Activldade "informal" & Machamba Imigrantes \\
\hline $\mathrm{N}^{\mathrm{o} 1}$ & Sim & Sim & I é mecânico na Toyota & $\begin{array}{l}1 \text { vende lenha em casa } \\
2 \text { arranjam motas no quintal } \\
2 \text { trabalham na machamba }\end{array}$ & Sim (duas) \\
\hline $\mathrm{N}^{2} 2$ & & & $\begin{array}{l}\text { I é funcionário público, } \\
\text { l é engenhleiro em Nairobi } \\
\text { l é técnica do M. Educ. }\end{array}$ & & 1 (Nairobi) \\
\hline $\mathrm{N}^{0} 3$ & & & 1 é reformado (lixo CMM) & 1 Constrói casas & \\
\hline $\mathrm{N}^{0} 4$ & & $\operatorname{Sim}$ & $\begin{array}{l}\text { I recebe pensão viuvez } \\
\text { lé empregada doméstica }\end{array}$ & IVenda de carvão & \\
\hline $\mathrm{N}^{0} 5^{\mathrm{a}}$ & & & $\begin{array}{l}\text { I é segurança } \\
\text { l é empregado de loja }\end{array}$ & 1 trabalha na machamba & 1 (RAS) \\
\hline $\mathrm{N}^{\circ} 6$ & $\mathrm{Sim}$ & Sim & I é segurança de Empresa & 1 vende petiscos em bares & Sim \\
\hline $\mathrm{N}^{\circ} 7$ & & Sim & $\begin{array}{l}1 \text { é barbeiro } \\
1 \text { é escriturário }\end{array}$ & $\begin{array}{l}\text { I Carpinteiro } \\
\text { IVendas malas e roupa } \\
\text { em casa }\end{array}$ & \\
\hline $\mathrm{N}^{\circ} 8$ & & $\operatorname{Sim}$ & lé encarregado obras & $\begin{array}{l}\text { I faz construção de casas } \\
\text { lé Curandeira } \\
2 \text { vendem à porta de casa } \\
\text { coisas variadas }\end{array}$ & \\
\hline $\mathrm{N}^{\circ 9}$ & Sim & Sim & & $\begin{array}{l}2 \text { vendem no "bar" em casa } \\
1 \text { traballha na machamba }\end{array}$ & Sim \\
\hline $\mathrm{N}^{\circ} 10$ & & Sim & 1 é reformado & I venda de carvão na estrada & \\
\hline $\mathrm{N}^{0} 11$ & & Sim & & I Vende no mercado & 1 (RAS) \\
\hline \multirow[t]{2}{*}{$N^{\circ} 12$} & & Sim & I é escriturário por & l é cabeleireira em casa & \\
\hline & & & $\begin{array}{l}\text { conta própria } \\
1 \text { é reformada }\end{array}$ & 1 trabalha na "banca?" & 1 (RAS) \\
\hline $\mathrm{N}^{0} 13$ & Sim & Sim & 1 Electricista & $\begin{array}{l}2 \text { são curandeiros } \\
1 \text { vende à porta de casa }\end{array}$ & Sim \\
\hline $\mathrm{N}^{\circ} 14$ & Sim & & $\begin{array}{l}\text { Reformado } \\
1 \text { Engenheiro. }\end{array}$ & $\begin{array}{l}\text { é professor em casa } \\
l \text { é condutor de "chapa" }\end{array}$ & 1 (RAS) \\
\hline $\mathrm{N}^{\circ} 15$ & & Sim & $\begin{array}{l}1 \text { é Padre de Mesquita e } \\
\text { mecânico na reforma } \\
1 \text { faz limpezas } \\
1 \text { é electricista CF }\end{array}$ & $\begin{array}{l}\text { I tem oficina de carpintaria } \\
2 \text { vendem à porta de casa } \\
1 \text { faz biscates em electricidade }\end{array}$ & 1 (RAS) \\
\hline$\overline{N^{\circ} 16}$ & & & & $\begin{array}{l}\text { lé curandeiro } \\
1 \text { faz biscates em electricidade }\end{array}$ & \\
\hline$N^{0} 17$ & & & & 2 são curandeiros & \\
\hline $\mathrm{N}^{\circ} 18$ & $\operatorname{Sim}$ & & & $\begin{array}{l}1 \text { biscales? } \\
1 \text { trabalha na machamba }\end{array}$ & Sim \\
\hline $\mathrm{N}^{0} 19$ & Sim & & $\begin{array}{l}\text { é dono de uma carpintaria } \\
1 \text { é contabilista de padaria } \\
\end{array}$ & 1 trabalha na machamba & 1 (RAS) \\
\hline $\mathrm{N}^{0} 20$ & & & $\begin{array}{l}\text { I é motorista } \\
\text { l é mecânico }\end{array}$ & & \\
\hline $\mathrm{N}^{0} 21$ & & & 1 é dono de oficina & & \\
\hline $\mathrm{N}^{2} 22$ & Sim & & I é Pastor Zione & 2 trabalham na machamba & $\overline{\text { Sim }}$ \\
\hline $\mathrm{N}^{0} 23$ & Sim & Sim & $\begin{array}{l}1 \text { recebe subsidio do INAS } \\
1 \text { é Motorista na RAS }\end{array}$ & $\begin{array}{l}1 \text { vende à porta de casa } \\
\text { I trabalha na machamba }\end{array}$ & 1 (RAS) \\
\hline
\end{tabular}


Assim, mesmo no bairro de Mafalala onde, e de acordo com os dados do Censo de 97, só $4 \%$ das agregados familiares tem um membro que trabalha na agricultura (contra $12 \% \mathrm{e}$ $14 \%$ nos outros bairros estudados) a actividade agrícola tem uma importância significativa na pequena amostra deste estudo, e essa importância não é apenas económica, mas advém também do valor simbólico que é atribuído à "terra de origem" e que funciona como um dos elementos de coesão do grupo familiar.

Nas 23 famílias entrevistadas, 10 beneficiavam de produtos agrícolas provenientes de machambas exploradas directamente por eles ou por outros familiares residentes no campo. Esses produtos agrícolas eram obtidos ou através de trabalho directo ou por troca de bens da "cidade" (açúcar, roupa, dinheiro...). Neste último caso, as trocas são efectuadas regularmente e podem ser uma importante fonte de sustento e implicam "trabalho" (deslocações, etc. ) e "investimento" por parte de quem as realiza. Nos casos em que a machamba é explorada pelos próprios, as situações são diferentes: tanto existem famílias que possuem terrenos agrícolas na periferia na cidade (e muitas vezes estes são de aquisição recente) e alguns dos seus membros (na maioria dos casos mulheres) deslocam-se diariamente ao local para o trabalharem. Como existem casos onde o terreno se situa mais longe, o que obriga a estadias na "machamba" mais ou menos prolongadas no tempo. Essas machambas podem ou não situar-se na "terra de origem" e, no caso afirmativo, podem lá residir parentes próximos que as trabalham (a primeira ou segunda esposa, pais, tios, irmãos,...).Existem ainda casos em que a familia usufruí de produtos agricolas provenientes de duas machambas, por exemplo, a machamba que se situa na "terra de origem" e a machamba de outra região explorada por outros membros da família. Estas diferentes situações, obrigam a que exista a já referida dispersão espacial da família. Temos membros da familia a residir em permanência nc bairro, outros membros que residem na região onde se situa a machamba e outros que são "itenerantes" e passam parte do seu tempo no bairro e parte do seu tempo no campo.

Como exemplo, podemos relatar o caso de uma das famílias entrevistadas em que a mãe reside em permanência no bairro com os seus filhos, mas efectua frequentes visitas à "terra de origem" (que neste caso é a terra da família do marido) levando "presentes" (roupa, sal, açúcar, dinheiro...) e recebendo em troca alguns produtos agrícolas que trás para Maputo e ajudam na alimentação da sua família. O pai, normalmente durante a semana, vive com ela no bairro, mas ao fim-de-semana e nas férias ou noutras ocasióes, desloca-se para uma

9 Este termo vai ser empregue de um modo simplista, para designar o local considerado pelos entrevistados como a sua "terra de origem". Esta "terra de origem" pode ser o local de nascimento do entrevistado(a), dos seus pais ou avós, ou de todos estes; no caso da entrevistada ser uma mulher, pode ser a terra do marido, ou de um primeiro marido já falecido ou de um de quem entretanto se separou. Pode ainda ser um outro local, onde estejam enterrados antepassados de há várias gerações, mas onde nenhum dos entrevistados ou seus familiares próximos nasceu ou residiu. A diversidade cultural dos entrevistados pode dar lugar a diferentes tipos de resposta e estes podem ainda designar como a sua "terra de origem" locais distintos em função da questão que o entrevistado lhes coloca. Por estas razões, e por muitas outras (GESCHIERE, 2000) esta questão de pertença a uma dada região é uma questão complexa e problemática e merece um tratamento aprofundado que não cabe nos objectivos desta comunicação." 
outra região, onde reside a sua segunda mulher. Esta é agricultora e ele, quando regressa dessas estadias, trás alguns produtos agrícolas para a sua casa de Maputo. Por sua vez, parte do salário que recebe do emprego que tem na cidade gasta-o nas deslocações e com essa segunda mulher. A situação não é do agrado da primeira mulher que se queixa e diz que a responsabilidade do sustento da família é toda dela pois o marido só lhe dá um terço do que ganha e isso não é suficiente. Para conseguir fazer face a todas as despesas ela desenvolve outra actividade geradora de rendimentos vendendo lenha à porta de casa.

As vendas são, como vimos, outra das actividades recorrentes das famílias e os vendedores são maioritariamente mulheres. Para subsistir e fazer face às suas responsabilidades "tradicionais" de provedoras do sustento da família, estas mulheres, em face da ausência de outras alternativas viáveis e muitas vezes na falta de terras que lhes permitissem exercer a sua actividade "tradicional" de produtoras agrícolas (6 das 11 familias que faziam vendas não tinham machamba) tiveram de inserir-se nos circuitos do chamado mercado informal, executando aí um leque muito variado de actividades - venda lenha, confeç̧ão e venda de alimentos, revenda de produtos importados, etc. Normalmente as crianças colaboram nesta actividade estando nas "bancas" sempre que é necessário

$\mathrm{O}$ facto das mulheres realizarem actividades que lhes permitem ter acesso ao dinheiro é uma importante mudança face à estrutura tradicional da sociedade moçambicana, mas isso não significa, de forma alguma, uma melhoria automática no seu estatuto ou uma libertação de outras tarefas domésticas. Pelo contrário, pode significar muitas vezes um acréscimo de trabalho e de responsabilidades. A mulher continua a ser responsável pela confecção das refeições da família e por todas as outras tarefas domésticas e muitas horas são despendidas a ir buscar água (nesta tarefa despendem muitas vezes 2 a 3 horas por dia dependendo da distância a que esta se encontra e das filas de espera no local onde se encontra), ou a procurar produtos mais baratos para cozinhar. Muitos desses produtos, nomeadamente a lenha, eram obtidos gratuitamente no campo e na cidade têm de os comprar.

No entanto, é evidente, de que o facto de as mulheres realizarem tarefas no exterior, e integrarem-se, por via de grupos informais de crédito, de Igrejas e de outras associações, em redes de solidariedade mais abrangentes do que as do parentesco, lhes confere a possibilidade de aceder a certas posições de poder e a ter uma certa visibilidade a nível do bairro que pode influenciar o seu estatuto na família. Mas a questão é a de saber como é que essas mudanças se processam e como se reequilibram (ou não) as relações no interior da familia face a alterações de estatuto de alguns dos membros. Por outro lado, a situação é obviamente diferente nos casos em que as famílias são alargadas e em que existem muitas mulheres nas diferentes faixas etárias podendo assim haver uma repartição hierárquica das diferentes tarefas e responsabilidades, ou nos casos em que as familias são nucleares e, por exemplo só existe uma mulher que sozinha tem de desempenhar todas as tarefas domésticas.

A maioria das familias entrevistadas serem famílias alargadas (Quadro $n^{\circ} 1 \mathrm{e} n^{\circ} 3$ ) e este dado coincide (na medida do possível, pois trata-se de unidades de análise distintas) com os dados do Censo de 1997 que referem que mais de metade dos agregados familiares são alargados (2.298 em 3.996) e pode ter várias explicações. Uma das explicações possíveis é de que num contexto de crise e de mudança profunda, com salários baixos e desemprego, 
ausência e/ou precariedade das estruturas estatais de protecção social, a família (ou cada um dos membros individualmente) tem mais possibilidades de garantir a sua sobrevivência e reprodução social quando consegue manter no grupo um elevado número de membros a realizar tarefas distintas.. Mas garantir a permanência desses membros dentro do mesmo núcleo familiar, não é certamente fácil ou possivel para todos, e vários entrevistados falaram de filhos que tinham partido para a África do Sul e nunca mais tinham regressado, maridos que tinham conhecido outra mulher e que não queriam saber nem da primeira, nem dos filhos que tiveram com ela, etc. Mas a impressão com que se fica é de que existe, independentemente de todos estes casos, a noção de que tudo é preferivel a solidão das pequenas familias.

Quadro n'3

Tipos de Familias

\begin{tabular}{|c|c|c|c|c|c|}
\hline$N^{0}$ membros & Alargada & $\begin{array}{c}\text { Alargada } \\
\text { patrilinear }\end{array}$ & Nuclear & monoparental & $\begin{array}{c}\text { Sem } \\
\text { informacão }\end{array}$ \\
\hline-6 & 5 & & 3 & & 1 \\
\hline 6 a 10 & 4 & & 2 & 7 & \\
\hline+10 & 6 & 1 & & & \\
\hline
\end{tabular}

Apresentados estes dados muitas questões continuam sem resposta. Como é gerida esta dispersão? Como é (ou não é, ou sou o é parcialmente) garantida a complementaridade das diferentes actividades produtivas?. Até que ponto existe uma correspondência entre a dispersão familiar, a coesão familiar e o seu relativo sucesso económico e social? Isto é, será que as famílias que se mantêm estruturadas são aquelas que têm um número relativamente elevado de membros distribuídos por diferentes ramos de actividade e em diferentes espaços geográficos? E será que esta situação é conjuntural, ou que perdura no tempo? E se assim for, será que o oposto se verifica? Famílias relativamente pequenas e residindo no mesmo espaço, com acesso a uma ou duas fontes de rendimento, são potencialmente mais frágeis económica e socialmente?

Obter um número suficientemente grande de respostas fiáveis para todas estas questões que se possa considerar representativo de um bairro com 21.189 pessoas é muito dificil. As respostas a muitas destas questões exigem um trabalho de terreno longo, com estudos de casos aprofundados que permitam conseguir o grau de intimidade suficiente entre as populações estudadas e o investigador. As pessoas têm as suas estratégias face aos desconhecidos que os questionam (e têm sido tantos, neste últimos tempos, em Moçambique) e muitas vezes têm relutância em responder a perguntas relacionadas com a proveniência e a gestão interna de rendimentos. (para não falar de muitas outras questões mais delicadas) Consideram, por vezes, que podem ter vantagens se apresentarem uma situação mais miserabilista do que de facto é e, algumas das fontes de rendimento, são de facto ilegais ou condenáveis socialmente e por isso não as revelam. Por último, as variáveis em presença e os imponderáveis são tantos que as pessoas muitas vezes não sabem, nem podem saber, qual o montante com que cada um contribuí para o orçamento familiar. Tudo depende, chega o 
irmão da África do Sul ou não, chove ou não, vendeu-se ou não, houve clientes ou não. É impossivel fazer contas, previsões num contexto onde praticamente tudo é imprevisivel.

Por outro lado, mesmo que haja uma resposta clara a essas questões, não é só a interdependência económica entre os membros de uma família que explica a coesão existente. Esse aspecto pode até ser a consequência e não causa da coesão existente.

A coesão familiar, pode ser explicada por outros factores, como seja a inserção das famílias em redes de solidariedade (as Igrejas fornecem um importante enquadramento) ou as relações entre estas e a "terra de origem".

A dependência entre os parentes vivos, passa muitas vezes por relações entre estes, os antepassados e a "terra de origem". E esta continua, pelo menos ideologicamente, a ser um importante referente, intimamente ligada ao culto dos antepassados e este culto (com adaptações) continua a ter muita importância no contexto actual, fornecendo algumas pistas que será importante explorar.

\section{BIBLIOGRAFIA}

1. BENDER, D. (1967) "A refinement of the concept of household: families, co-residence, and domestic functions" in American Anthropologist 69: 493-503.

2. BOURDIEU, P.(1980) Le Sens Pratique Les Éditions de Minuit, Paris, 1980.

3. BOURDIEU, P. (1972) "Les Stratégies Matrimoniales dans le Systéme de Reproduction", Annales E.S.C., Famille et Société, 27e année, 4-5, pp.1105-1127.

4. BRYCESON, D. F. (1995) "Gender relations in rural Tanzania: power politics or cultural consensus" in, CREIGHTON, C.(ed.), Gender, Family and Household in Tanzania, Aldershot, etc.: Avebury, pp.37-69.

5. CASTRO, A., (1980) O Sistema Colonial Português em Africa Lisboa, Editorial Caminho.

6. COSTA, A., B. (1995) "Estudo de famílias deslocadas na cidade de Maputo: análise das relações e comportamentos sócio-económicos" Dissertação de Mestrado, Lisboa, Instituto Superior das Ciências do Trabalho e Empresas (ISCTE).

7. CREIGHTON, C. \& OMARI, C.K.(1995) "Introduction", in: CREIGHTON, C.(ed.), Gender, Family and Household in Tanzania, Aldershot, etc.: Avebury, pp.1-31.

8. CROW, G. (1989) "The use of the concept of 'strategy" in Sociology, vol.23, n'1, pp.124.

9. GESCHIERE, P.(2000) "The Processes of Disaggregation and social recomposition. The Village and New Modes of the "Politics of Belonging"" Presentation for the International Conference Africa at the Turn of the Century, Lisbon, 20-23 September 2000.

10. INSTITUTO NACIONAL DE ESTATÍSTICA (1998), II Recenseamento Geral da População e Habitação. 1997, Resultados Definitivos, Maputo.

11. LOFORTE, A. M.(1996) "Género e Poder entre os Tsonga de Moçambique", Tese de Doutoramento, Lisboa, Instituto Superior das Ciências do Trabalho e Empresas (ISCTE). 
12. LE BRIS, E. et all (orgs.)(1987), Famille et résidence dans les villes africaines, Paris: L'Harmattan.

13. OLIVIER de SARDAN, J., P.(1985) "Sciences sociales, africanistes et faits de dévelopement" Boiral, P., (org.) Paysans, Experts et Chercheurs en Afrique Noire, Paris, Karthala.

14. OLIVIER de SARDAN, J., P. (1998)_Anthropologie et Développement, Paris, Karthala.

15. PENA PIRES, R., (1993) "A imigração em Portugal- Ensaio de uma tipologia" Recent migration trends in Europe: Europ's new architecture, Rocha Trindade, M.B. (org.) Universidade Aberta, Instituto de Estudos para o Desenvolvimento, Lisboa.

16. RAPOSO, I. \& QUINTELA, J.(2000) "A Reinvenção do Urbano" Cidades UCCLA n"2, pp.28-41.

17. YANAGISAKO, S. J. (1979) "Family and household: the analysis of domestic groups" Annual Review of Anthropology, Vol.8, pp. 161-205.

18. WLSA Moçambique (1997) Families in changing environment in Mozambique Women and law in Southern Africa (WLSAMOZ), Maputo, 1997. 